\title{
FACTORES CLAVE EN LA IMPLEMENTACIÓN DE POLÍTICAS ENER- GÉTICAS EN ITALIA
}

\author{
Pedro Joaquín Chévez ${ }^{1 *}$; Emilia Ruggeri ${ }^{2}$;rene Martini $^{1}$ y Carlos Discoli $^{1}$ \\ 1 Instituto de Investigaciones y Políticas del Ambiente Construido (IIPAC). Consejo Nacional de Investigaciones \\ Científicas y Técnicas. Universidad Nacional de La Plata. CP 1900 La Plata, Buenos Aires, Argentina. \\ 2 Instituto de Estudios sobre la Ciencia y la Tecnología. Universidad Nacional de Quilmes. CP B1876 Bernal, \\ Buenos Aires, Argentina. \\ *chevezpedro@gmail.com
}

Artículo enviado: 07/03/2019. Aceptado el 06/06/2019

Publicado en 11/06/2019

\section{RESUMEN}

Actualmente, la implementación de medidas de eficiencia energética (EE) y energías renovables (ER) se encuentra en la agenda política de numerosos países; sin embargo, el avance concreto y la implementación efectiva de dichas estrategias es aún muy dispar. Si bien existen países donde dichas tecnologías han recalado efectivamente en sus regímenes socio-técnicos; una gran mayoría aún no comenzó a enfrentar dicha transición de manera sistémica y, por consiguiente, deberán afrontar numerosos desafíos. En tal sentido, este trabajo presenta un análisis de la transición energética que se está desarrollando de forma sostenida en el sector residencial italiano desde mediados de la década del 2000 (20062016) a los efectos de identificar, sistematizar y extraer factores clave del caso de estudio. A partir de éstos es posible discutir acerca de la implementación de políticas energéticas y generar insumos para otros casos de estudio que pretendan impulsar medidas estatales de mejoramiento energético.

PALABRAS CLAVE: eficiencia energética; energías renovables; Italia; sector residencial.

\section{KEY FACTORS IN THE IMPLEMENTATION OF ENERGY POLICIES IN ITALY}

\begin{abstract}
Currently, the implementation of energy efficiency strategies (EES) and renewable energy sources (RES) is inside of the political agenda of many countries. However, the concrete progress in the effective implementation of these policies is still very different. On the one hand, there are specific cases of countries where the aforementioned technologies have been inserted effectively into their socio-technical regimes and the transition is ongoing. On the other hand, the vast majority of countries has not yet begun to face this process and, therefore, will have to face challenges and difficulties. In this regard, this paper presents an analysis of the energy transition that is developing steadily in the Italian residential sector from the mid-2000s (2006-2016). This analysis made it possible to identify, systematize and extract key factors from the case study; from which it is possible to discuss and generate inputs for other cases of study that intend to implement state policies for energy improvement.
\end{abstract}

KEYWORDS: energy efficiency; renewable energy; Italy; residential sector. 


\section{INTRODUCCIÓN}

Actualmente se presenta un escenario donde se ha vuelto ineludible replantear la dependencia hacia los combustibles fósiles. En esta dirección, algunas acciones como el mejoramiento de la eficiencia energética de los usos finales, en el marco de una transición energética hacia matrices que incorporen fuentes no convencionales, son alternativas que podrían dar respuesta, al menos parcial, al problema energético actual. En relación a ello, para el año 2016 un 74\% de los países contaban con políticas de eficiencia energética (EE) y un $57 \%$ con políticas de inserción de fuentes de energías renovables (ER) (REN 21, 2018).

En tanto, a nivel mundial, el consumo de energía del sector residencial tiene una participación significativa sobre el consumo de energía total, cuya incidencia es del 23\% (IEA, 2015). Es por ello que focalizando sobre dicho sector, y mejorando sus patrones de consumo, es posible incidir de forma concreta sobre el consumo de energía total. Bajo este contexto, a nivel mundial se han buscado estrategias para que el sector residencial logre consumir de forma eficiente e incluso genere parte su energía. Por ejemplo, en Europa, desde la década de 1970 luego del shock petrolero, pero fundamentalmente desde mediados de la década del 2000, se han lanzado paquetes de medidas muy ambiciosas con el objetivo de reducir el consumo energético e incorporar energías renovables. Sus objetivos principales fueron contribuir a la seguridad energética, disminuir la dependencia de las importaciones de combustibles fósiles, reducir los precios de la energía, movilizar la economía y contribuir a la reducción de las emisiones de gases de efecto invernadero (GEI) (Parlamento Europeo, 2012).

A pesar de ello, a nivel mundial, el avance concreto en la implementación efectiva de dichas estrategias es aún muy dispar. Por un lado, existen casos puntuales, fundamentalmente los países desarrollados, donde las la EE y las ER han calado efectivamente en los hogares y la transición se encuentra en curso. Por otra parte, la gran mayoría de los países aún no comenzó a enfrentar dicho proceso y, por consiguiente, deberán afrontar diferentes desafíos y dificultades.

En este contexto es posible identificar ejemplos concretos donde la mencionada transición energética se está desarrollando de forma efectiva sobre el sector residencial. A partir del indicador ODEX, que representa la mejora en la eficiencia energética residencial, es posible verificar que en el período 2000-2015 Suecia, Rumania, Irlanda, Holanda, Eslovaquia, Reino Unido, Letonia, Austria y Alemania presentan los valores más altos de Europa. Sus valores rondan entre el 30\% y $40 \%$ (ADEME, 2018). Por su parte, en el caso de Italia, si bien la transición está en curso, dado que se han readecuado las normativas y se han lanzado programas específicos de incentivos, su desarrollo presentó ciertas circunstancias que han desacelerado el proceso y, por su parte, su clima difiere de los países previamente citados, por lo que la comparativa no puede ser directa. En consecuencia su valor ODEX para el mencionado período es del 10,3\% (ADEME, 2018). Por lo tanto, se trata de un caso de estudio de interés del cual es posible extraer factores clave que dinamizaron su avance, como así también aquellos que lo desaceleraron.

En cuanto a la aplicación de políticas e incentivos para la promoción de EE y ER en Italia, es posible identificar trabajos que abordan la temática desde diversos enfoques. En este sentido, el trabajo de Alberini y Bigano (2015) evalúa los incentivos destinados al sector residencial para el reemplazo de sistemas de calefacción por medio de encuestas a propietarios de viviendas. El trabajo de Sarrica et al. (2018) explora cómo las perspectivas alternativas asociadas con la sostenibilidad energética se trasladan, respaldan o son resistidas a lo largo de las diferentes escalas gubernamentales (nivel nacional, regional y local). En el caso de Galatioto, Ciulla y Ricciu (2017), se analiza el estado del arte del patrimonio residencial italiano, como así también las posibles soluciones de reciclado energético. Asimismo, en Prete et al. (2017) se analizan elementos actitudinales, normas subjetivas, comportamiento e indicadores de preocupación ambiental para investigar la intención de 
adoptar medidas de eficiencia energética por parte de los ciudadanos italianos. En Caputo y Pasetti (2017) se analizan los aspectos que influencian la renovación energética por parte de los actores privados (dueños de edificios, administradores, ciudadanos y compañías) utilizando un modelo basado en GIS. Por otro lado, en Chiaroni et al. (2016) se realiza un análisis de la viabilidad económica de medidas de eficiencia energética por medio de un indicador denominado LEEC (Levelized Energy Efficiency Cost). Finalmente, en Chang et al. (2017) se estudia la efectividad de los gobiernos de la OCDE en materia de implementación de medidas de EE entre 1990 y 2014.

En base a la revisión bibliográfica, se detecta que existen escasos trabajos que hayan abordado el estudio de la implementación de EE y ER desde una perspectiva de innovación tecnológica o transición tecnológica en Italia y que, a partir de su análisis, generen insumos para la formulación de políticas energéticas. En este sentido, es posible identificar trabajos que utilizan este enfoque pero en otros casos de estudio, por ejemplo: en Ardanche et al. (2017) se estudia la inserción de la energía eólica en Uruguay; en Geels y Johnson (2018) se estudian los modelos de adopción de sistemas socio-técnicos utilizando como caso de estudio a la difusión de los sistemas de calefacción distrital por biomasa en Austria; en Kungl y Geels (2018) se analiza la desestabilización de la industria eléctrica en Alemania, la cual enfrentó múltiples presiones externas por parte de las tecnologías renovables, por políticas de reducción de participación nuclear, por la crisis económicafinanciera, entre otros; en Geels et al. (2018) se utiliza una perspectiva multi-nivel para formular escenarios socio-técnicos en la transición del sistema eléctrico de Reino Unido; mientras que en Rogge, Pfluger y Geels (2018) se utiliza una metodología equivalente para analizar la transición del sistema eléctrico Alemán hacia las energías renovables.

En base a la problemática energética identificada y a los antecedentes relevados, el presente trabajo plantea un análisis sobre la transición energética que se está desarrollando en Italia, particularmente en el sector residencial entre los años 2006 y 2016, donde la inserción de ER y la incorporación de estrategias de EE están configurando un nuevo sistema tecnológico. Dicho cambio se comenzó a impulsar desde el Estado nacional de forma sostenida a partir de mediados de la década del 2000 pero, al mismo tiempo, no ha avanzado con la velocidad que presentan otros países europeos, lo cual permite identificar tanto elementos dinamizadores como ralentizadores. Para estudiar el mencionado proceso, se utiliza el marco conceptual de transiciones tecnológicas y sistemas de innovación analizados desde una perspectiva multi-nivel de Elzen et al. (2004), el cual permite comprender las dinámicas de cambio socio-técnicos. Dicho análisis permitió identificar, sistematizar y extraer factores clave del caso de estudio; los cuales fueron utilizados para discutir sobre los aspectos diversos que se necesitan considerar durante la implementación de políticas estatales de mejoramiento energético en otros casos de estudio.

\section{ACERCA DE LAS TRANSICIONES EN SISTEMAS TECNOLÓGICOS}

Para analizar las transformaciones del sector residencial italiano se utiliza la perspectiva integradora multi-nivel planteada por Elzen et al. (2004), la cual permite el estudio de transiciones tecnológicas. En relación a ello, se entiende que las transiciones tecnológicas son grandes cambios tecnológicos de largo plazo en el modo en que las funciones sociales son satisfechas y, por ende, involucran cambios en la tecnología, cambios en prácticas de usuarios, regulaciones, redes industriales, infraestructura y significados culturales. (Ardanche et al., 2017)

Dentro de la mencionada aproximación teórica se distinguen tres niveles conceptuales para comprender un sistema socio-técnico, los cuales no son descripciones ontológicas de la realidad, pero son conceptos analíticos para comprender la dinámica compleja de los cambios socio-técnicos. En este sentido, se plantea la diferenciación entre: el paisaje socio-técnico; el régimen socio-técnico y los nichos tecnológicos. Los tres se definen a continuación. 


\subsection{Paisaje socio-técnico}

Es posible afirmar que las trayectorias tecnológicas se sitúan dentro del paisaje sociotécnico, el cual consiste en un conjunto de profundas tendencias estructurales. El término denota la relativa estabilidad y el contexto material de la sociedad, tales como la disposición de las ciudades, industrias, infraestructuras energéticas, entre otras. Asimismo, incluye un conjunto de factores de cambio lento como valores culturales o normativos, coaliciones políticas, desarrollos económicos de largo plazo, problemas ambientales, etc. Pero también contiene cambios radicales o shocks. El paisaje socio-técnico es el contexto externo para los actores de los nichos y los regímenes, cuyos factores son difíciles de cambiar.

\subsection{Regímenes socio-técnicos}

En cuanto a los regímenes socio-técnicos, es posible plantear que los elementos y vínculos en el sistema socio-técnico son el resultado de actividades de grupos sociales que lo reproducen.

Los miembros de cada grupo social comparten percepciones, problemas de agenda, normas, preferencias, terminologías, tienen asociaciones profesionales, etc. Estos grupos coexisten bajo un mismo sistema, donde se desarrollan diferentes regímenes, por ejemplo el régimen tecnológico (diseño y producción), el régimen político, el régimen científico, el régimen socio-cultural y el régimen de los usuarios/mercado. A su vez, dichos regímenes interactúan entre sí, formando redes con interdependencias. (Geels, 2005)

Las actividades de estos grupos están alineadas con los restantes y, a su vez, coordinadas. Para comprender dicha coordinación, Geels (2005) utiliza el término de régimen socio-técnico. El cual refiere a un conjunto de reglas realizadas y reproducidas por distintos grupos sociales y son estos regímenes los que sostienen la estabilidad del sistema socio-técnico vigente.

En esta instancia es preciso destacar que para que los artefactos funcionen, se requiere de aspectos funcionales como elementos organizacionales, infraestructuras, regulación, etc. Se trata de tecnologías en contexto, las cuales funcionan dentro de sus propios dominios, por ejemplo los hogares, el sistema de transporte, etc., los cuales están regidos por regulaciones, prácticas del usuario, significados simbólicos, entre otras. (Geels, 2005)

\subsection{Nichos tecnológicos}

Por último, es necesario destacar que los regímenes generan innovaciones incrementales, mientras que las innovaciones radicales se producen en los nichos. Éstos están protegidos de los mecanismos de selección de mercado, actúan como incubadoras de novedades radicales, dado que las nuevas tecnologías en sus inicios suelen tener baja performance, pueden ser engorrosas de aplicar e incluso costosas.

Por su parte, los nichos se conciben como campos organizacionales donde distintas comunidades interactúan de acuerdo a reglas compartidas y acciones coordinadas. A su vez, los actores crean, constituyen y modifican las reglas. En este sentido, las innovaciones desarrolladas en el nivel de nicho pueden evolucionar al nivel del régimen cuando las relaciones entre actores se vuelven más estrechas y las reglas se tornan más estables y precisas.

\subsection{Interrelación entre los tres niveles conceptuales}

Las interacciones en los distintos niveles son diversas. En los nichos hay una débil estructuración y coordinación, los vínculos sociales son precarios. Mientras tanto, en los regímenes, las interacciones son mucho más fuertes, con reglas más estables y mayor coordinación entre actores. El paisaje socio-técnico provee una estructuración mucho más fuerte, donde el ambiente material, las 
creencias culturales, símbolos y valores son difíciles de separar.

Siguiendo a los autores (Elzen et al., 2004), la relación entre los tres conceptos se puede entender como una relación de jerarquía anidada, lo cual significa que los regímenes están insertos en el paisaje, y los nichos en los regímenes.

Las novedades en los nichos están dirigidas a resolver problemas en los regímenes existentes y los actores presentes en los nichos esperan que las novedades se utilicen en el régimen o reemplacen otros. Sin embargo, los vínculos dentro de los regímenes hacen que sean difíciles las inserciones de novedades. En consecuencia, las novedades comienzan como insignificantes y, a menudo, sirven para resolver problemas concretos, pero si la novedad logra alinearse para crear una configuración de funcionamiento, la misma puede insertarse gradualmente dentro del régimen vigente (diseños dominantes). Para que las novedades puedan salir del nivel del nicho, se deben generar las condiciones externas propicias y crear o detectar ventanas de oportunidad. Una vez que la innovación se introduce en los mercados masivos, entra en competencia con el régimen existente y puede, eventualmente, reemplazarlo. Esto debe ser acompañado por cambios más amplios en el régimen socio-técnico, por ejemplo cambios regulatorios, infraestructura, redes industriales, etc.

Asimismo, puede haber dos explicaciones para las transiciones: circunstancias externas o patrones internos. Los procesos dentro del régimen socio-técnico o el paisaje pueden proveer ventanas de oportunidad que emergen cuando se encuentran tensiones entre los elementos del régimen o cuando las actividades de los grupos sociales están desalineadas. Por ejemplo puede suceder: (i) que el paisaje presione sobre el régimen; (ii) que ciertos problemas técnicos internos creen oportunidades en el régimen; (iii) que las externalidades negativas presionen sobre el régimen; (iv) que ocurran cambios en las preferencias de los usuarios; (v) que la competencia entre empresas abra el campo a nuevos productos o (vi) que haya un refuerzo en los vínculos entre determinados grupos sociales y esto habilite a la difusión de una tecnología.

En este sentido, utilizando el concepto de paradigma tecno-económico, Carlota Pérez (2003) sostiene que en los periodos de cambio de paradigmas, se abren ventanas de oportunidad para formalizar dichos cambios. A su vez, la autora sostiene que el paradigma puede servir como impulsor de la difusión pero también como fuerza ralentizadora de las nuevas tecnologías. Es impulsor porque brinda un modelo que puede ser seguido por todos, pero su configuración lleva tiempo alrededor de una década o más-. Mientras que este desarrollo debe sobreponerse a las resistencias iniciales fundamentadas en las fuerzas de la inercia producto de los éxitos del pasado con el paradigma anterior, cuya predominancia es el principal obstáculo para la difusión de la siguiente revolución.

Finalmente, siguiendo con la conceptualización de Elzen et al. (2004), es necesario destacar que en la transición hacia un nuevo sistema tecnológico se pueden identificar cuatro fases: Durante la primera fase, la novedad emerge en un contexto determinado, surge para resolver problemas puntuales y fundamentalmente se maneja en el nivel de nicho. En la segunda fase ocurre el desarrollo y la especialización técnica en los mercados nicho y la exploración de nuevas funcionalidades, donde es fundamental contar con reglas y competitividad para que la tecnología se difunda. En la tercera fase se da la amplia difusión y competencia dentro del régimen establecido, y una vez que la tecnología y las reglas básicas se estabilizaron, la difusión puede ocurrir y ésta depende de oportunidades externas, mejoras en el precio/eficiencia del producto o en un fortalecimiento de los vínculos entre actores. Por último, en la cuarta fase se da el reemplazo gradual del régimen establecido, la nueva tecnología reemplaza a la vieja de forma gradual creando nuevas prácticas en los usuarios, nuevas políticas y formas de organización. 


\section{CONTEXTO ENERGÉTICO DEL CASO DE ESTUDIO}

En relación al caso de estudio, el sector civil italiano (edificios) demanda aproximadamente el $37 \%$ de la energía total utilizada, seguido por transporte con un $31 \%$ e industria con un $21 \%$, mientras que agricultura, no energético y bunker cubren el restante $11 \%$. Asimismo, los resultados de la aplicación de las políticas de EE y ER indican que la demanda neta de energía ha comenzado a caer durante la última década (Figura 1 y Figura 2). A su vez, se verifica un crecimiento considerable en la utilización de fuentes renovables (Figura 1) y un estancamiento en el consumo neto del sector edilicio, a pesar del crecimiento vegetativo (Figura 2). Al mismo tiempo, además de la inserción de las políticas energéticas, Italia ha experimentado una reducción del consumo energético neto por la recesión económica ocasionada por la crisis global del año 2008 y por los cambios ocurridos en la economía global donde los servicios están incrementando su participación en el PBI de los países centrales. (ENI Scuola, 2016)

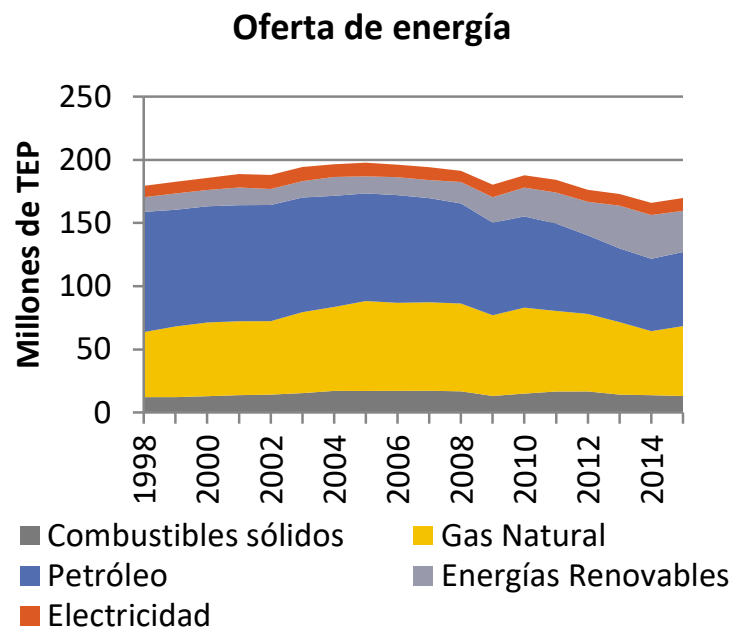

Figura 1.- Trayectoria de la oferta energética en Italia. Fuente: MiSE (2018)

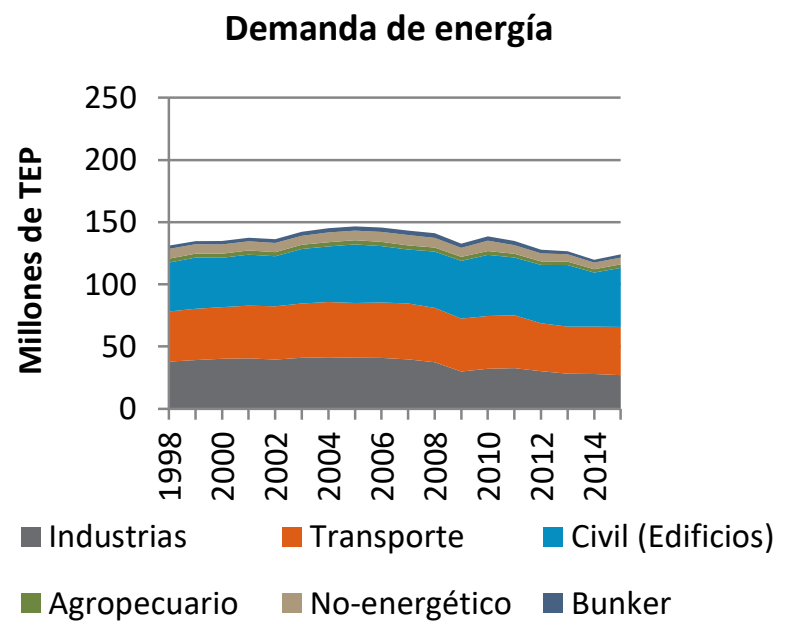

Figura 2.- Trayectoria de la demanda energética en Italia. Fuente: MiSE (2018)

Por otro lado, analizando la generación eléctrica local es posible resaltar que las centrales de gas natural dominan la matriz $(43,55 \%)$; luego la generación de energía hidroeléctrica $(14,60 \%)$ y los combustibles sólidos $(12,30 \%)$ tienen una participación importante. Por su parte, las energías renovables tienen una alta penetración en la matriz eléctrica, cuyos valores se exponen a continuación: plantas fotovoltaicas $(7,64 \%)$, biomasa $(6,69 \%)$, energía eólica $(6,09 \%)$ y geotérmica $(2,17 \%)$ (ARERA, 2017). Por ende, la generación termoeléctrica es dominante, generando una gran dependencia del gas natural, cuyo abastecimiento depende en un 91\% de importaciones (ARERA, 2017).

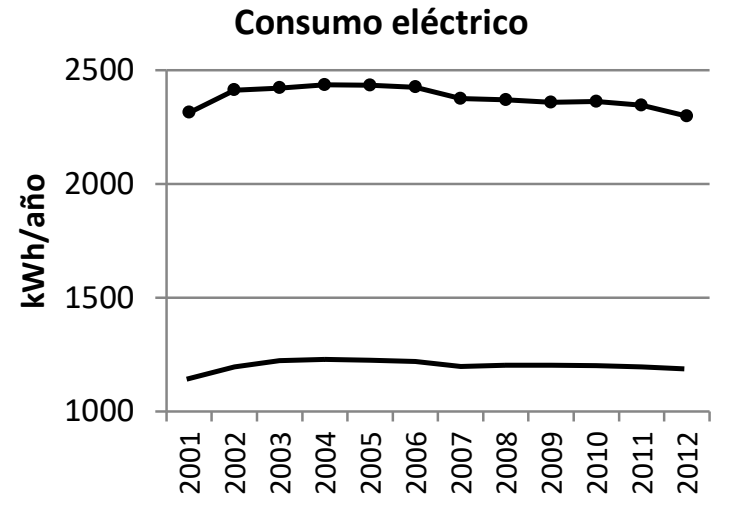

Figura 3.- Trayectoria del consumo eléctrico per cápita y por usuario. Fuente: ISTAT (2018a)

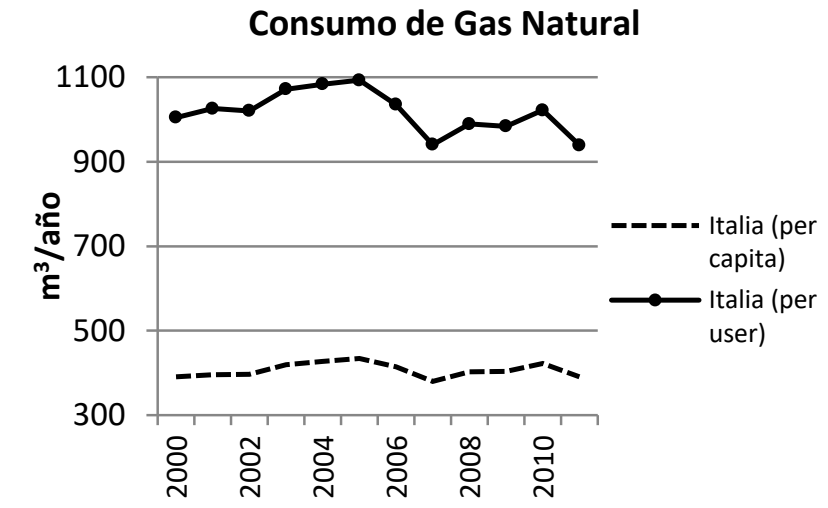

Figura 4.- Trayectoria del consumo de gas natural per cápita y por usuario. Fuente: ISTAT (2018a) 
En cuanto a los patrones de consumo energético residencial, en las Figura 3 y Figura 4 se puede observar que: la demanda de electricidad por usuario bajó de un promedio de $2407 \mathrm{kWh} / \mathrm{año}$ (2001-2006) a $2298 \mathrm{kWh} /$ año en 2012; mientras que la demanda de gas natural por usuario pasó de un promedio de $1054 \mathrm{~m}^{3} /$ año (2001-2006) a $938 \mathrm{~m}^{3} /$ año en 2012. Esto significa una reducción del $4,5 \%$ y $11,0 \%$ respectivamente.

\section{ANÁLISIS DE LA TRANSICIÓN ENERGÉTICA EN EL SECTOR RESI- DENCIAL ITALIANO}

Tal como se ha podido verificar, en Italia ha habido una clara reducción en el consumo de energía residencial, como así también un incremento en la participación de las energías renovables sobre la matriz energética; cuyos agentes movilizadores son analizados a continuación por medio de del marco teórico-conceptual multi-nivel. A los efectos de identificar la trayectoria de las políticas energéticas que se aplican en el territorio -ciudades-, en el marco de decisiones institucionales y reglamentaciones establecidas en ámbitos de decisión mayores -nacionales o regionales-, se utiliza como caso de estudio a la ciudad de Bolonia y su inserción dentro del contexto italiano y de la Unión Europea (UE). Para su análisis, se relevó información bibliográfica y se desarrollaron entrevistas a actores claves del sector gubernamental, privado y científico-universitario.

\subsection{Contexto energético y problemas ambientales: condicionantes del paisaje socio-técnico}

Luego de la crisis del petróleo en la década del setenta, diversos países de la Unión Europea (UE) debieron emprender acciones para enfrentar las fuertes variaciones de precios impuestas por los países que concentraban dicho recurso (Rosenfeld, 2007). Posteriormente, la problemática ambiental comenzó a ser tomada en consideración, a tal punto de que los países centrales se comprometieron a disminuir sus niveles de emisiones de GEI con la firma de sucesivos tratados, como por ejemplo: la Declaración de Río sobre el Medio Ambiente y el Desarrollo (1992); el Protocolo de Kyoto (1997); o la conferencia Río+20 (2012). En base a dichos antecedentes, durante la década del noventa, y en mayor medida en las décadas siguientes, la UE lanzó sucesivas normativas energéticas sobre: eficiencia energética de edificios (Directiva 31/2010 y 27/2012); equipamiento domiciliario (Regulación 2010/30 y 2017/1369); promoción de energías renovables (Directiva 28/2009); y liberalización de los sistemas energéticos (Directiva 92/1996, 54/2003 y 72/2009). Todas ellas, tal como afirma el Parlamento Europeo (2012), orientadas a enfrentar los retos ocasionados por la creciente dependencia de las importaciones de energía y a la escasez de recursos energéticos, así como a la necesidad de limitar el cambio climático y superar la crisis económica de 2008.

En relación a ello, la UE considera que la EE y las ER son un medio valioso para mejorar la seguridad de abastecimiento y reducir el consumo de energía primaria, las importaciones y las emisiones de GEI de manera rentable. Por su parte, sostiene que el cambio a una economía energéticamente más eficiente puede acelerar la difusión de soluciones tecnológicas innovadoras y mejorar la competitividad de la industria, impulsando el crecimiento económico y creando empleos de alta calidad en diversos sectores. A partir de dicho cuerpo regulatorio, los países miembro debieron promulgar sus propias leyes orientadas a cumplir los objetivos estipulados por la UE. En ese marco, Italia sancionó su legislación en la temática para lograr un alineamiento político con la normativa europea y por el hecho de contar con problemáticas energéticas similares a los restantes países de la UE (Gaspari, 2018). En relación a ello, es de destacar que la matriz de energía primaria italiana depende en un $67 \%$ del petróleo y del gas natural, los cuales son importados en más de un $95 \%$ y $90 \%$ respectivamente. (MiSE, 2018)

Asimismo, durante la última década los costos internacionales de las energías renovables 
han disminuido notablemente (IRENA, 2017; 2018). La energía eólica y solar fotovoltaica comenzaron a ser competitivas con algunas tecnologías de generación convencional, principalmente por la gran cantidad de potencia instalada en países como China o Estados Unidos. En contraposición, se observa que los precios del petróleo durante los últimos diez años han alcanzado valores elevados en relación a períodos previos, contando con una media de 80,85 USD/barril (2006-2015), mientras que en durante el período previo dicho costo se posicionó en unos 28,81 USD/barril (1996-2005). (Federal Reserve Bank of St. Louis, 2018)

Por lo tanto, el paisaje -o contexto- presionó directamente sobre los Estados de la UE para que los mismos comenzaran a sostener transiciones en sus sistemas energéticos, a partir de fortalecer y hacer emerger tecnologías que se venían desarrollando intensamente en nichos desde mediados de la década del setenta. Los acuerdos ambientales generaron un peso considerable en materia política y, por ende, algunas administraciones decidieron adoptarlos como políticas activas (Gaspari, 2018) y, en ciertas poblaciones, fueron considerados como factores de importancia (Fini, 2018). Por consiguiente, se entiende que actualmente en Italia se está desarrollando una transición de un régimen socio-técnico inicial con usuarios consumidores de baja eficiencia energética, hacia un régimen futuro con usuarios prosumidores de alta eficiencia energética.

Por su parte, la crisis de 2008, ha tenido un fuerte impacto sobre las economías de los países de la UE y, por transición, sobre la implementación de políticas de EE y ER. Una de las consecuencias en Italia fue que la importante expansión del sector de la construcción -previo a la crisis- dejó una gran sobreoferta de viviendas vacías de baja calidad, dado que éstas fueron edificadas previamente a las normativas más rigurosas de estándares termo-energéticos de 2010/2012 (Antonini, 2018). Este gran volumen de viviendas vacantes y la fuerte recesión económica genera una ralentización en la incorporación de nuevas unidades de vivienda de alta eficiencia térmica, lo cual dificulta la disminución de los consumos de climatización que son los de mayor participación dentro de la demanda residencial. Tal como se verifica en la Tabla 1, el promedio de viviendas nuevas durante el período 2005-2007 era de 263 mil unidades por año, mientras que para el período 2008-2011 el promedio descendió a 141 mil por año y entre 2012-2016 a 52 mil por año.

Tabla 1.- Permisos de construcción para nuevos edificios y para ampliaciones de edificios existentes en Italia.

\begin{tabular}{|c|c|c|c|c|}
\hline & \multicolumn{2}{|c|}{ Nuevas edificaciones } & \multicolumn{2}{|c|}{ Ampliación de edificaciones existentes } \\
\hline Año & Viviendas cant. & Superficie habitable útil (m2) & Viviendas (cant.) & Superficie habitable útil (m2) \\
\hline 2005 & 278602 & 20479027 & 27104 & 2169149 \\
\hline 2006 & 261455 & 19143787 & 28436 & 2272912 \\
\hline 2007 & 250271 & 18383339 & 26431 & 2086441 \\
\hline 2008 & 191783 & 14268787 & 23263 & 1859979 \\
\hline 2009 & 141587 & 10703097 & 18867 & 1540195 \\
\hline 2010 & 119409 & 9366218 & 9298 & 781441 \\
\hline 2011 & 112570 & 9163218 & 8908 & 712970 \\
\hline 2012 & 82058 & 6652196 & 8759 & 685975 \\
\hline 2013 & 53408 & 4582120 & 7592 & 591307 \\
\hline 2014 & 46796 & 4019992 & n.d. & n.d. \\
\hline 2015 & 40932 & 3494602 & n.d. & n.d. \\
\hline 2016 & 40479 & 3631387 & n.d. & n.d. \\
\hline
\end{tabular}

Fuente: ENEA (2018)

En este contexto de parálisis de la industria de la construcción, los programas para el mejoramiento de los edificios existentes han tomado mayor impulso, tanto para reactivar dicho sector como para reducir la demanda de energía (ver Tabla 2 más adelante). En línea con lo referido al impacto de la crisis de 2008, Carlota Pérez (Iranzo, 2009) sostiene que la misma puede dar lugar a una época de bonanza global y sustentable como forma de despliegue de la sociedad del conocimiento. Dicha afirmación se fundamenta en que, históricamente, las grandes oleadas tecnológicas han vivido un gran auge financiero que terminaron en un estrepitoso colapso. Sin embargo, sistemáticamente, la recesión posterior y la indignación popular traen al Estado de nuevo al ruedo a controlar al mundo financiero, a favorecer al capital productivo. Esta etapa genera un auge que aprovecha 
las nuevas tecnologías para innovar y crecer a todo lo ancho del aparato productivo, con tendencia al pleno empleo y a una mejor distribución de los beneficios del crecimiento. Sin embargo, para que ello ocurra se requiere de un reacomodo institucional importante a nivel mundial y en cada país, para controlar la especulación financiera y reorientar la inversión hacia las actividades productivas. En consecuencia, la mencionada conceptualización concuerda con lo sucedido en el caso de estudio, donde el Estado optó por direccionar las acciones hacia una ventana de oportunidad generada por un gran stock de viviendas existentes ineficientes energéticamente.

Por su parte, distintos actores entrevistados confirman que, en la actualidad, la mencionada crisis también genera dificultades en el acceso al crédito para aquellos usuarios que desean emprender intervenciones a nivel habitacional. Asimismo, otra situación que ralentiza la difusión de las distintas medidas en Italia es la edad de la población (Satta, 2018; Gaspari, 2018), la cual cuenta con una alta cantidad de personas de edad avanzada y una pirámide poblacional del tipo "envejecida". Esta situación presenta una dificultad a la hora de lidiar con incentivos que tienen un período de recuperación que ronda los diez años.

\subsection{Hacia la difusión de las tecnologías de ER y la EE: el régimen socio-técnico actual}

En cuanto al régimen socio-técnico, el mismo se encuentra en una transición entre: (i) un sistema de consumidores de energía con baja eficiencia energética en la edificación y equipamiento, con generación eléctrica concentrada, estatal y altamente dependiente de los combustibles fósiles modelo de década del 80- ; y (ii) un sistema con prosumidores distribuidos, orientados a la electrificación de los usos energéticos, con alta eficiencia energética en las construcciones y el equipamiento, con una menor concentración de la generación eléctrica, con una alta participación de las ER y un modelo privado de libre mercado - modelo impulsado en la década del 2000-.

Bajo este contexto de transición, entre 2006 y 2016, más de 3 millones de viviendas han realizado intervenciones energéticas por medio de la incorporación de estrategias de mejoramiento (ENEA, 2018), siendo de 24 millones de viviendas el parque edilicio para el año 2011 (ISTAT, 2018b). Las intervenciones realizadas se orientaron mayormente a: generación FV; colectores solares de agua caliente sanitaria; mejoramiento de la envolvente edilicia; y el mejoramiento en la eficiencia del equipamiento de climatización, mayoritariamente de calefacción.

Todas estas tecnologías han sido desarrolladas en sus correspondientes nichos tecnológicos $\mathrm{y}$, actualmente, han comenzado a calar o emerger dentro del régimen establecido a partir de diversas políticas de incentivos impulsadas por el gobierno italiano y en el marco de la UE.

En este sentido, en relación a la difusión y la coordinación de los intereses nacionales en las jurisdicciones más pequeñas, como las regiones o municipios, diversos entrevistados afirman que no existen espacios de articulación entre los distintos estamentos de gobierno para alinear acciones. Sin embargo, tal como afirman Gaspari (2018) y Fini (2018), la tradición histórica autonómica de "ciudades-estado" que presentan las ciudades o regiones italianas favoreció para que cada una de éstas, en mayor o menor medida, avanzara de forma independiente en cuanto al desarrollo local de la temática energético, complementando las políticas de incentivos directos lanzadas por la administración nacional. Asimismo, las ciudades contaron con un marco común de discusión a nivel europeo, el cual fue constituido por la iniciativa denominada "Covenant of Mayors" que se inició en 2008. Dicho espacio habilitó a los firmantes a intercambiar experiencias de gestión, solicitar fondos y otras acciones. En el caso de Italia, al no existir a nivel nacional una iniciativa equivalente, la misma fue muy beneficiosa, siendo alrededor de un $50 \%$ de las ciudades firmantes italianas (3319/6855). (Covenant of Mayors Office, 2018)

Otro punto de interés dentro del régimen socio-técnico vigente es el de la información para el usuario. En el caso de la ciudad de Bologna, el usuario que pretende realizar una intervención 
puede acudir de forma gratuita a una oficina coordinada por la Confederazione Nazionale dell'artigianato e della Piccola e Media Impresa (CNA), donde puede asesorarse sobre aspectos técnicos, pero también de incentivos nacionales, como así también iniciar la gestión de los mismos. Esta oficina, denominada "Punto Energia", al ser sostenida por la CNA (a partir del llamado del Municipio), está impulsada por las pequeñas y medianas industrias, las cuales en última instancia son aquellas que realizan los trabajos de mejoramiento en las viviendas. La CNA tiene una vinculación directa con los distintos estamentos de gobierno y actualiza permanentemente la información referida a normativa e incentivos. Si bien la difusión de la existencia de esta oficina es muy escasa (Ranieri, 2018), su funcionamiento es un importante ejemplo de coordinación público-privada.

A pesar de lo enunciado previamente, la normativa constructiva orientada a la edificación nueva, lanzada desde la UE, el gobierno italiano y las diferentes regiones, cuenta como limitación la escasa incorporación de nuevas unidades por el impacto de la crisis económica internacional. No obstante, los nuevos edificios se construyen con una alta calidad termo-energética y, a su vez, deben incorporar sistemas renovables. Lo cual tiene estrecha relación con el hecho de que son tecnologías que la población logra reconocer y aceptar, dado que se han ido generando exigencias por parte del mercado y, en consecuencia, por parte de los clientes (Satta, 2018).

En consecuencia, ante la escasa incorporación de viviendas nuevas, actualmente las mayores posibilidades de mejorar la eficiencia energética edilicia recaen en el reciclado de los edificios existentes. En esta línea, la intervención sobre la edilicia existente sirvió para movilizar la economía, generar puestos de trabajo, contribuir con el ahorro energético, entre otras alternativas. Sin embargo, su implementación es compleja dado que una gran cantidad de viviendas en Italia está inserta en edificios multifamiliares [cerca de un 50\% (ISTAT, 2018b)]. Allí coexisten diversas tipologías de familias, las cuales pueden presentar condiciones que impidan la concreción de intervenciones, por ejemplo: edad avanzada, bajos ingresos, la condición de tenencia, desinterés u otras. Por lo tanto, en muchos casos las intervenciones deben verse restringidas a la realización de una única acción como la sustitución de ventanas o de los sistemas de climatización. En relación a ello, los mecanismos de incentivos han tomado en consideración las principales problemáticas detectadas y ha actualizado las condiciones de los mismos: los incentivos son superiores en edificios multifamiliares; las detracciones fiscales se pueden transferir a las empresas constructoras, lo cual facilita el acceso al incentivo para aquellos que cuentan con una tributación baja; se abrieron incentivos con plazos de devolución más cortos, lo cual permite incluir a personas de edad avanzada; entre otras alternativas.

Por otra parte, un aspecto pendiente para la UE en esta transición es la liberalización definitiva de los mercados energéticos, que aún no ha logrado los objetivos deseados ya que la gran mayoría de los usuarios todavía permanecen en el mercado protegido por el Estado, cuya tarifa es regulada (Anderlini, 2018). Otro aspecto a resolver es el del financiamiento para los usuarios en este contexto de rigidez para el acceso al crédito.

A modo de síntesis, la Figura 5 expresa la actual configuración del régimen socio-técnico. Allí puede observarse la interacción entre los diferentes grupos sociales o actores: las distintas escalas de gobierno, UE, Italiano, Regional, Municipal; el sector científico-universitario; el sector financiero; el sector privado (empresas energéticas, constructoras, fabricantes de materiales, profesionales/técnicos); asociaciones público-privadas como la CNA y el municipio; y usuarios. Es notorio que para la efectiva promoción de las innovaciones tecnológicas, se precisa de la alineación de diferentes fuerzas para promover los cambios. En este sentido, en la siguiente sección se describe el proceso de inserción de tecnologías de ER y EE en el medio real.

\subsection{El desarrollo de largo plazo de las tecnologías de EE y ER: evolución en nichos tecnológi- cos e inserción al régimen socio-técnico}

En la presente sección interesa describir los procesos por los cuales se han comenzado a in- 
cluir las tecnologías de paneles fotovoltaicos, colectores solares térmicos, de mejoramiento de envolvente y sistemas eficientes de climatización dentro del régimen socio-técnico.

Las tecnologías han sido desarrolladas en los nichos tecnológicos y, en el caso italiano, han comenzado a recalar en el régimen vigente gracias a la implementación de programas de incentivos muy fuertes como "Conto Energia Fotovoltaico", "Detrazione fiscale" y "Conto Energia Termico".

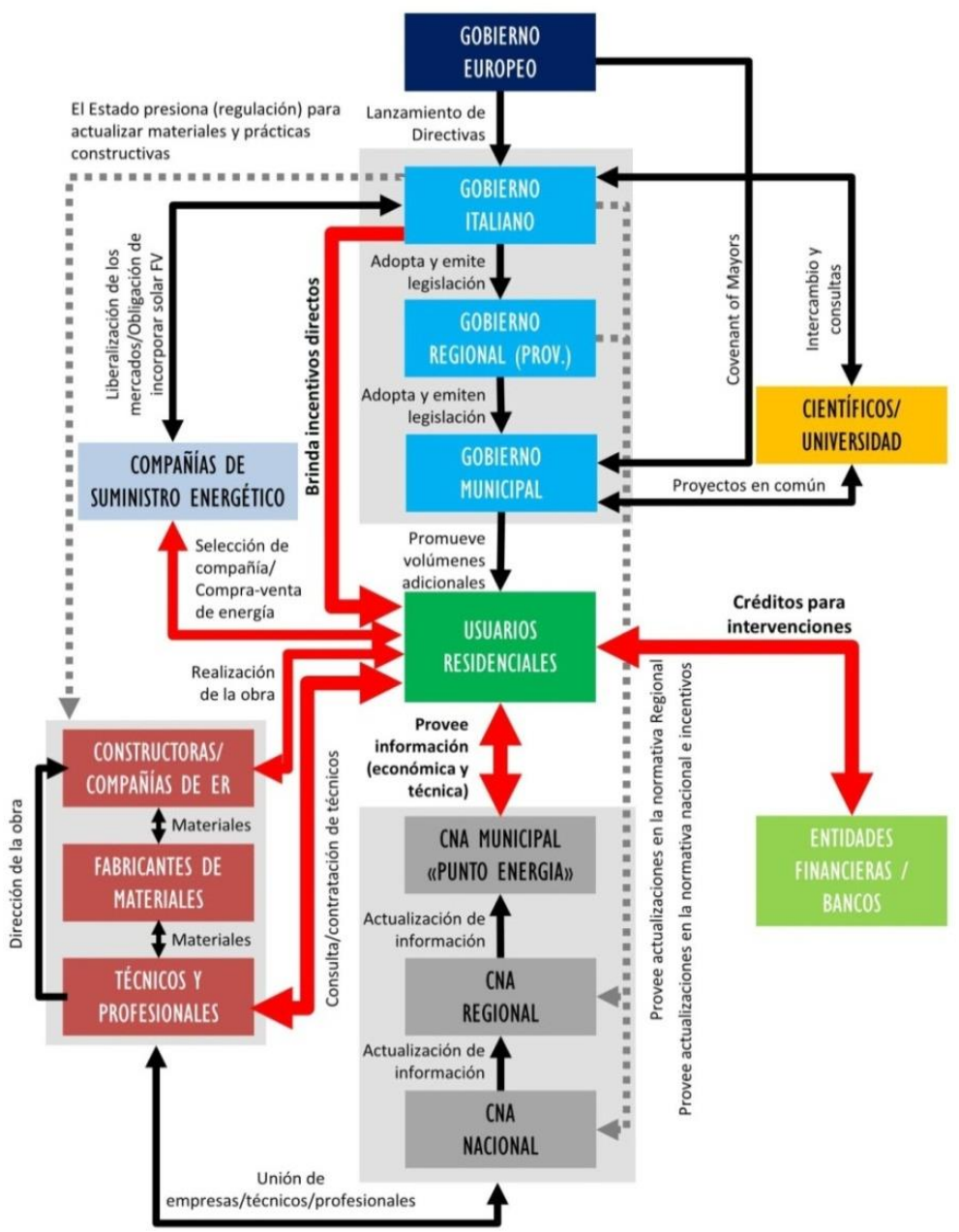

Figura 5.- Reproducción del régimen socio-técnico en el caso de Bolonia (Italia). Fuente: Elaboración propia.

\subsubsection{Avances en energía solar fotovoltaica}

En cuanto a la energía solar fotovoltaica, a nivel internacional, ésta tuvo sus primeras aplicaciones masivas dentro de la industria espacial, principalmente en la década de 1960. Luego, en la década de 1970, a partir de la crisis del petróleo, se incrementó la inversión destinada a I+D en este campo, logrando mejorar el desarrollo de las celdas. En consecuencia, se logró descender su precio desde 100 USD/W hasta 40-20 USD/W (Solar Power Authority, 2018). Esto posibilitó su utilización en diversos tipos de instalaciones, entre ellas edificios y plantas de generación. A partir de mediados de la década del 2000, se produjo un nuevo descenso en los costos de los sistemas hasta alcanzar el valor de 4,50 USD/W en 2010 y 1,79 USD/W en 2017 (IRENA, 2017), principalmente por la ampliación de las economías de escala en países como China. En este sentido, su penetración a nivel mundial se ha incrementado exponencialmente, pasando de $6 \mathrm{GW}$ instalados en 2006 a 303 GW instalados en 2016, tal como se observa en la Figura 6.

El instrumento utilizado por el gobierno italiano para difundir el uso de la energía fotovoltaica fue el programa denominado "Conto Energia Fotovoltaico", el cual asegura el pago a toda la 
energía generada por un instalación fotovoltaica en nuevas construcciones, refacciones o repotenciamiento, para sistemas mayores a $1 \mathrm{~kW}$ conectados a la red eléctrica por un tiempo de 20 años con una tarifa preferencial. Dicha tarifa dependía del tipo de sistema, el mes del año, entre otros aspectos, los cuales oscilaban entre $0,20 € / \mathrm{kWh}$ a $0,55 € / \mathrm{kWh}$. (CNA, 2011)

Este sistema de incentivos entró en funcionamiento en 2005 a partir de decretos interministeriales, en lo que se denominó "ler Conto Energia". En 2007 inició el "2do Conto Energia" con algunas características nuevas como la simplificación de las reglas de acceso a las tarifas de incentivo, la diferenciación de las tarifas según el tipo de integración arquitectónica, el tamaño de la planta y la combinación con el uso eficiente de la energía. En 2010, comenzó el "3er Conto Energia", aplicable a las plantas que entraron en servicio desde el 1/1/2011 y hasta el 31/5/2011, que introdujo tarifas específicas para sistemas fotovoltaicos integrados con características innovadoras y fotovoltaicas la concentración. El "4to Conto Energia" comenzó en 2011 y definió el mecanismo de incentivo para las plantas que entraron en servicio después del 31/5/2011 con el objetivo de alinear el nivel de tarifas con la evolución de los costos de la tecnología fotovoltaica e introducir un límite de incentivos de costos anuales acumulados, fijado en $€ 6$ mil millones. El "5to Conto Energia" se lanzó en 2012 y extendió dicho monto a $€$ 6,7 mil millones. Las disposiciones de incentivo para este programa se suspendieron el 6 de julio de 2013 después de alcanzar el límite máximo establecido.

Una vez finalizadas todas las ediciones del programa "Conto Energia", el único mecanismo de soporte para la incorporación de energía fotovoltaica es el esquema denominado "Scambio sul Posto" (intercambio en el lugar) y una reducción en los impuestos para la inversión de los sistemas a instalar. El "Scambio sul Posto" es un mecanismo de acumulación virtual de energía, en la cual se utiliza la red de distribución como sistema acumulador. El usuario compra la energía a la distribuidora y, por otro lado, l'Autorità per l'Energia Elettrica ed il Gas le abona al usuario la energía inyectada a la red a precio de mercado. (CNA, 2013)

En base a los instrumentos utilizados para incentivar el uso de la energía solar FV, Italia ha incorporado unos 19,3 GW de los mencionados $303 \mathrm{GW}$ instalados a nivel mundial. Sin embargo, tal como se puede verificar en la Figura 7, con el fin del incentivo de "Conto Energia" en 2013 en Italia se desaceleró el ritmo de incorporación de potencia instalada en FV. Por su parte, a pesar de los esfuerzos positivos impulsados en distintos sectores del sistema eléctrico italiano, la gobernanza y la regulación del mismo no han avanzado al mismo nivel que la incorporación de la tecnología, lo cual impide el desarrollo de los mercados eléctricos dispersos. (Gaspari y Lorenzoni, 2018)

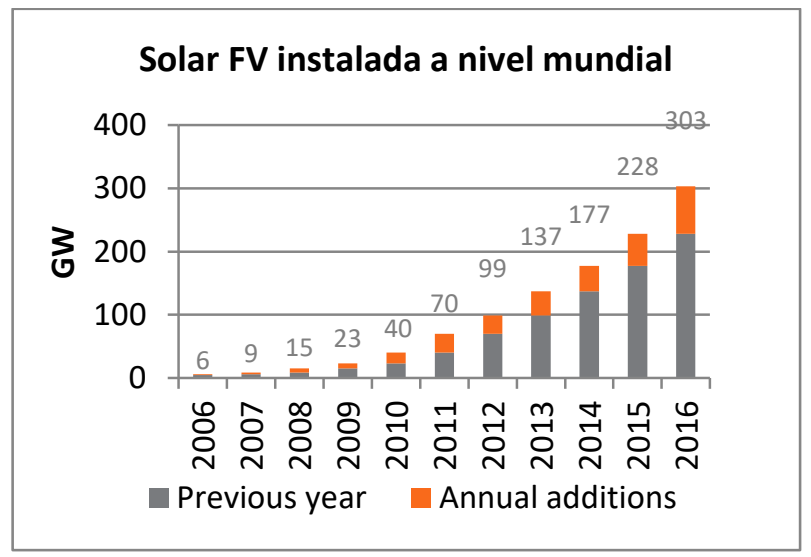

Figura 6.- Energía Solar FV instalada a nivel mundial. Fuente: REN 21 (2017)

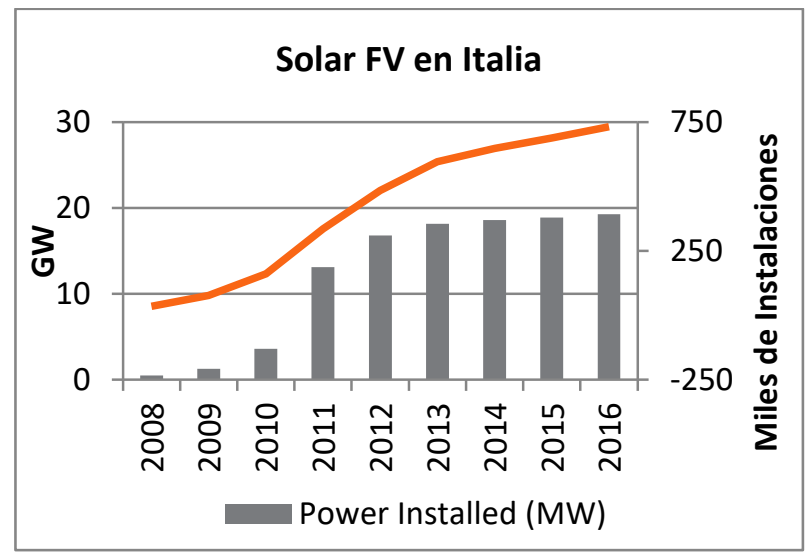

Figura 7.- Solar FV instalada en Italia entre 2008 y 2016. Fuente: GSE (2017)

\subsubsection{Avances en energía solar térmica y eficiencia energética}

A nivel internacional, el primer lugar en hacerse extensivo el uso de la energía solar térmica para el calentamiento de agua fue en el Estado de California entre 1900 y 1920, como así también 
en el sur del Estado de Florida entre 1920 y 1940 (NAS, 1976). Luego de 1950, los diseños de colectores solares fueron mejorados sustancialmente por países como Israel, Australia y Japón, que en la década del 1970 comenzaron a implementarlos de forma extensiva. Los principales avances logrados en la década de 1990 en la tecnología y producción de tubos de vacío de vidrio permitieron a China desarrollar una línea de producción de diseño propio y comenzar la producción en serie de calentadores de agua solares del tipo Heat Pipe. Todos estos logros en investigación, puesta en la producción, han contribuido a la mejora constante del rendimiento de los colectores y su consecuente reducción de sus costos, lo que generó un fuerte impulso a la industria termosolar de China y, por consiguiente, de numerosos países a nivel mundial (Runqing, Peijun y Zhongying, 2012). En relación a ello, se estima que la potencia instalada pasó de $124 \mathrm{GW}_{\text {th }}$ en 2006 a $456 \mathrm{GW}_{\text {th }}$ en 2016 equivalente a unos 646 millones de $\mathrm{m}^{2}$-, cuyo incremento muestra un comportamiento prácticamente lineal -Figura 8-. (REN 21, 2017)

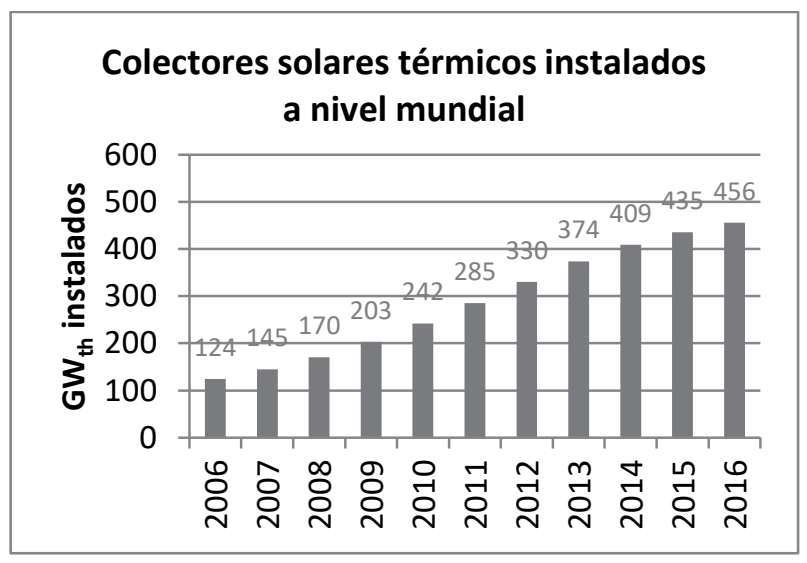

Figura 8.- Colectores solares de agua instalados a nivel mundial. Fuente: REN 21 (2017).

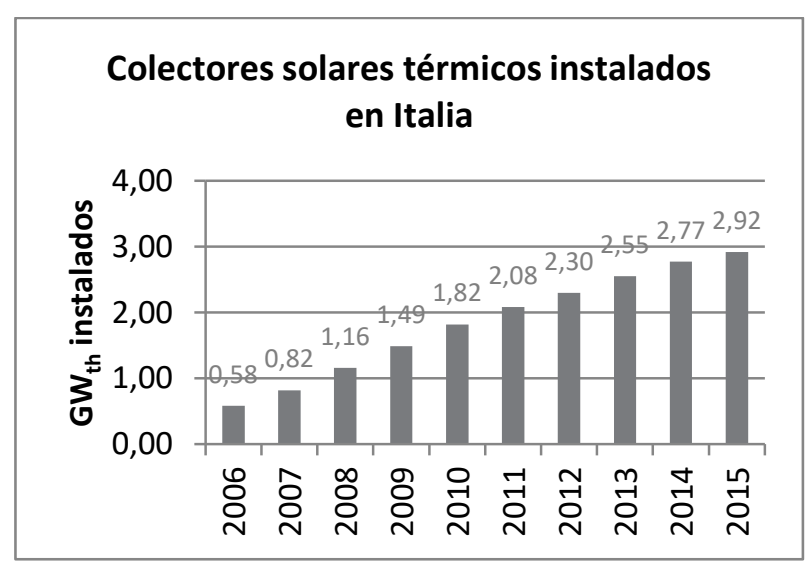

Figura 9.- Colectores solares térmicos instalados en Italia. Fuente: ESTIF (2018)

En el caso del mejoramiento de la envolvente edilicia y la sustitución de los sistemas de climatización, los antecedentes en la implementación de este tipo de políticas también se remontan fundamentalmente a la década de 1970, producto de la crisis del petróleo, donde los países centrales apuntaron al reciclado de las estructuras existentes, a la construcción de nuevas viviendas más eficientes y en el equipamiento de calefacción (Rosenfeld, 2007). Por su parte, en la década de 1990 la mayoría de los países europeos occidentales implementaron o profundizaron en dichas estrategias, tanto por la presión ejercida por el cambio climático como por la seguridad en el abastecimiento (IEA, 2008). En la actualidad, en Europa se está consiguiendo mejorar el comportamiento de las edificaciones existentes, a tal punto de lograr reducciones en sus consumos por vivienda del orden de del 22\% entre el año 2000 y 2015 (pasando de 1,18 a 0,92 TEP/vivienda*año; REN 21, 2017).

En el caso particular italiano, para el impulso de la energía solar térmica, el mejoramiento de la eficiencia energética en las construcciones existentes y las instalaciones de climatización se utilizaron incentivos muy importantes para su fomento: la "Detrazione fiscale" y el "Conto Termico".

La "Detrazione fiscale", aprobada en 2006, está orientada a todos los contribuyentes, ya sean personas físicas, profesionales, sociedades y empresas. Son aplicables para intervenciones llevadas a cabo en edificios existentes pertenecientes a cualquier categoría de registro de propiedad. $\mathrm{Su}$ objetivo es promover la recalificación energética global de los edificios existentes y apoyar las consiguientes mejoras energéticas (CNA, 2018). Este incentivo realiza una deducción del impuesto a las ganancias brutas (IRPEF o IRES) - tasa diferenciada según el tipo de intervención- de los gastos incurridos en la recalificación energética hasta el 31/12/2018 para las viviendas individuales y hasta el 31/12/2021 para las intervenciones llevadas a cabo en las partes comunes de los edificios multifamiliares. La devolución del monto cubierto por el incentivo se realiza en diez años y el porcentaje de cobertura y el monto de la deducción máxima (DM) depende del tipo de intervención: 
- Las intervenciones para acceder a una devolución del 50\% del monto del trabajo se refieren a: reemplazo de sistemas de calefacción por calderas de condensación (DM: $€ 30$ mil); intervenciones relativas a ventanas (DM: €60 mil); instalación de sistemas de protección solar (DM: €60 mil); e instalación de sistemas de calefacción por biomasa (DM: €30 mil).

- Las intervenciones para acceder a una devolución del $65 \%$ del monto del trabajo se refieren a: recalificaciones energéticas generales (DM: $€ 100$ mil); aislamiento de estructuras opacas verticales y horizontales (DM: $€ 60$ mil); reemplazo de instalaciones existentes con microcogeneradores que produzcan un ahorro de energía primaria de al menos 20\% (DM: €100 mil); instalación de colectores solares de agua (DM: $€ 60$ mil); reemplazo de sistemas de calefacción por bombas de calor de alta eficiencia, plantas geotérmicas de baja entalpía, calderas de condensación o sistemas híbridos con bomba de calor más caldera de condensación (DM: €30 mil); reemplazo de calentadores de agua tradicionales por sistemas con bomba de calor (DM: $€ 30$ mil); e instalación de dispositivos de control remoto para los sistemas domiciliarios (€30 mil).

- Para los condominios, a partir de la Ley de Presupuesto 2017, se adopta una tasa de devolución del $70 \%$ para intervenciones sobre la envolvente edilicia que superen un $25 \%$ de la superficie expuesta; y un $75 \%$ de tasa para las intervenciones sobre los sistemas de climatización (DM: $€$ 40 mil por cada vivienda del condominio).

Por otro lado, el "Conto Energia Termico", aprobado en 2013 una vez discontinuado el programa de "Conto Energia Fotovoltaico", se orientó a la producción de energía térmica a partir de fuentes renovables o al mejoramiento de la eficiencia energética de pequeña dimensión en edificios existentes (CNA, 2016). El programa está dirigido tanto para la administración pública como a las personas físicas privadas. Asimismo se estableció un monto máximo total acumulado para las intervenciones, cuyos valores ascienden a $€ 200$ millones y $€ 700$ millones respectivamente. Las características del incentivo se describen a continuación:

- Las medidas incluidas en este programa están referidas a: aislamiento térmico; sustitución de ventanas; sustitución del sistema de calefacción por calderas a condensación, bombas de calor, sistemas por biomasa o solares; sustitución de equipos de calentamiento de agua eléctricos por bombas de calor; elementos de control solar; sustitución del equipamiento de iluminación; automatización de los sistemas de climatización; y medidas tendientes a transformar al edificio en un "edificio a energía casi cero".

- Cada tipo de intervención puede ser cubierta desde un $40 \%$ hasta un 65\%, dependiendo del tipo de intervención y de la región climática. El reembolso económico se realiza en cuotas anuales (5 años para intervenciones de EE y entre 2-5 años para ER). En este sentido, la sustitución de sistemas de climatización por bombas de calor se abona un monto en $€ / \mathrm{kWt}$ según la potencia instalada, el COP del sistema y la región climática; para el recambio de sistemas de calentamiento de agua por equipos por bomba de calor se cubre hasta un $40 \%$ del monto (máximo $400 € / 700 €$ según la capacidad). Finalmente, para la instalación de colectores solares de agua se abona un monto por la energía producida en $€ / \mathrm{kWh}$ y si el monto total no supera los $€ 5$ mil se reintegra en un solo pago.

- El programa se orienta a intervenciones más reducidas que la "Detrazione fiscale", tiene un tiempo de retorno más rápido, no se devuelve por medio de impuestos y, por lo tanto, habilita a que los sectores con menores recursos puedan acceder a los incentivos. (Ranieri, 2018)

A partir de la descripción previa es posible identificar que las tecnologías que se incluyen en los programas de incentivos italianos han tenido un largo proceso de desarrollo dentro de nichos tecnológicos, los cuales se intensificaron durante la década de $1970 \mathrm{y}$, en mayor medida, durante la década del 2000. Una vez abierta la oportunidad dentro del régimen vigente, a partir de los factores 
enunciados en el nivel de paisaje y del propio régimen, bajo la intervención estatal y el lanzamiento de diversos programas, las mencionadas tecnologías comenzaron a emerger e instalarse dentro del régimen socio-técnico. Algunos resultados de su implementación se exponen a continuación.

En cuanto a la inserción de la energía solar térmica, según datos de ESTIF (2018), en Italia, y a pesar de la crisis económica, la energía solar se confirma como el segundo mercado europeo con un total instalado $2,92 \mathrm{GW}_{\text {th }}\left(4,14\right.$ millones de $\mathrm{m}^{2}$; Figura 9), principalmente gracias a la aplicación del programa de "Detrazione fiscale" y, en menor medida, el "Conto Energia Termico". Cabe señalar que en toda Europa se han instalado unos 35,13 $\mathrm{GW}_{\text {th }}$ (más de 50 millones de $\mathrm{m}^{2}$ ).

En cuanto a las intervenciones realizadas sobre edificios existentes, éstas también han sido realizadas por medio de los mecanismos de la "Detrazione fiscale" y "Conto Energia Termico". En cuanto a la "Detrazione fiscale", para contar con un orden de magnitud (ver Tabla 2), entre el año de inicio del incentivo (2007) y el 2016 se realizaron unas 2,8 millones de intervenciones para recalificación energética (valuadas en $€ 31$ mil millones), las cuales producen un ahorro de 1,08 Mtep/año. Por su parte, también se ejecutaron unas 11,5 millones de intervenciones orientadas a la recuperación edilicia sin objetivos energéticos (valuadas en $€ 205$ mil millones), desde el año de inicio de dicho programa (1998) y el 2016, generan ahorros de 1,8 Mtep/año (ENEA, 2018). Por lo tanto, entre ambas iniciativas se ahorran unos 2,88 Mtep/año, sobre los 46,89 Mtep/año que consume el sector edilicio en Italia. En cuanto a la participación de las diferentes intervenciones sobre el ahorro total de energía realizadas por medio de la "Detrazione fiscale" para la recalificación energética, se detecta la siguiente distribución: la aislación de muros, la sustitución de cerramientos y la incorporación de protecciones solares producen cerca de un 50\% de los ahorros anuales; cerca de un $40 \%$ del ahorro es producido por la incorporación de sistemas de calefacción eficientes; mientras que el resto es cubierto por otras intervenciones. En tanto, con el "Conto Energia Termico", entre el año de inicio (2013) y 2016 se han logrado realizar unas 25 mil intervenciones que generan un ahorro de 0,0025 Mtep/año. Las intervenciones que mayor peso representan sobre el ahorro total conseguido son: la instalación de calderas de condensación (45\%); incorporación de aislación térmica a la envolvente opaca (36\%); sustitución de ventanas (18\%); y otras intervenciones completan el resto $(1 \%)$.

Tabla 2 - Intervenciones realizadas con la "Detrazione fiscale" (para recuperación edilicia sin fines energéticos y para recalificación energética).

\begin{tabular}{lrrrr}
\hline \multirow{2}{*}{ Año } & \multicolumn{2}{c}{ Recuperación edilicia } & \multicolumn{2}{c}{ Recalificación energética } \\
& Intervenciones & Monto (M€) & Intervenciones & Monto (M€) \\
\hline $\mathbf{1 9 9 8}$ & 240413 & 3385 & - & - \\
$\mathbf{1 9 9 9}$ & 254989 & 3590 & - & - \\
$\mathbf{2 0 0 0}$ & 273909 & 4392 & - & - \\
$\mathbf{2 0 0 1}$ & 319249 & 5119 & - & - \\
$\mathbf{2 0 0 2}$ & 358647 & 5750 & - & - \\
$\mathbf{2 0 0 3}$ & 313537 & 5666 & - & - \\
$\mathbf{2 0 0 4}$ & 349272 & 4888 & - & - \\
$\mathbf{2 0 0 5}$ & 342396 & 6848 & - & - \\
$\mathbf{2 0 0 6}$ & 371084 & 6313 & 106000 & 453 \\
$\mathbf{2 0 0 7}$ & 402811 & 7938 & 247800 & 3500 \\
$\mathbf{2 0 0 8}$ & 391688 & 7365 & 236700 & 2563 \\
$\mathbf{2 0 0 9}$ & 447728 & 8070 & 405600 & 4608 \\
$\mathbf{2 0 1 0}$ & 494006 & 8705 & 280700 & 3099 \\
$\mathbf{2 0 1 1}$ & 779400 & 14400 & 245234 & 2891 \\
$\mathbf{2 0 1 2}$ & 883600 & 16325 & 355961 & 3849 \\
$\mathbf{2 0 1 3}$ & 1317627 & 24345 & 294281 & 3066 \\
$\mathbf{2 0 1 4}$ & 1366416 & 25246 & 331128 & 3088 \\
$\mathbf{2 0 1 5}$ & 1195438 & 25732 & 360267 & 308 \\
$\mathbf{2 0 1 6}$ & 1392705 & Fute: & & - \\
\hline
\end{tabular}




\subsubsection{Situación actual de la transición}

En la actualidad, siguiendo el marco conceptual de transiciones tecnológicas, es posible afirmar que en el caso italiano, la inserción de las ER y el mejoramiento de la EE se encuentra entre las fases de transición de "amplia difusión y competencia dentro del régimen establecido" (tercera fase) y de "reemplazo gradual del régimen establecido" (cuarta fase).

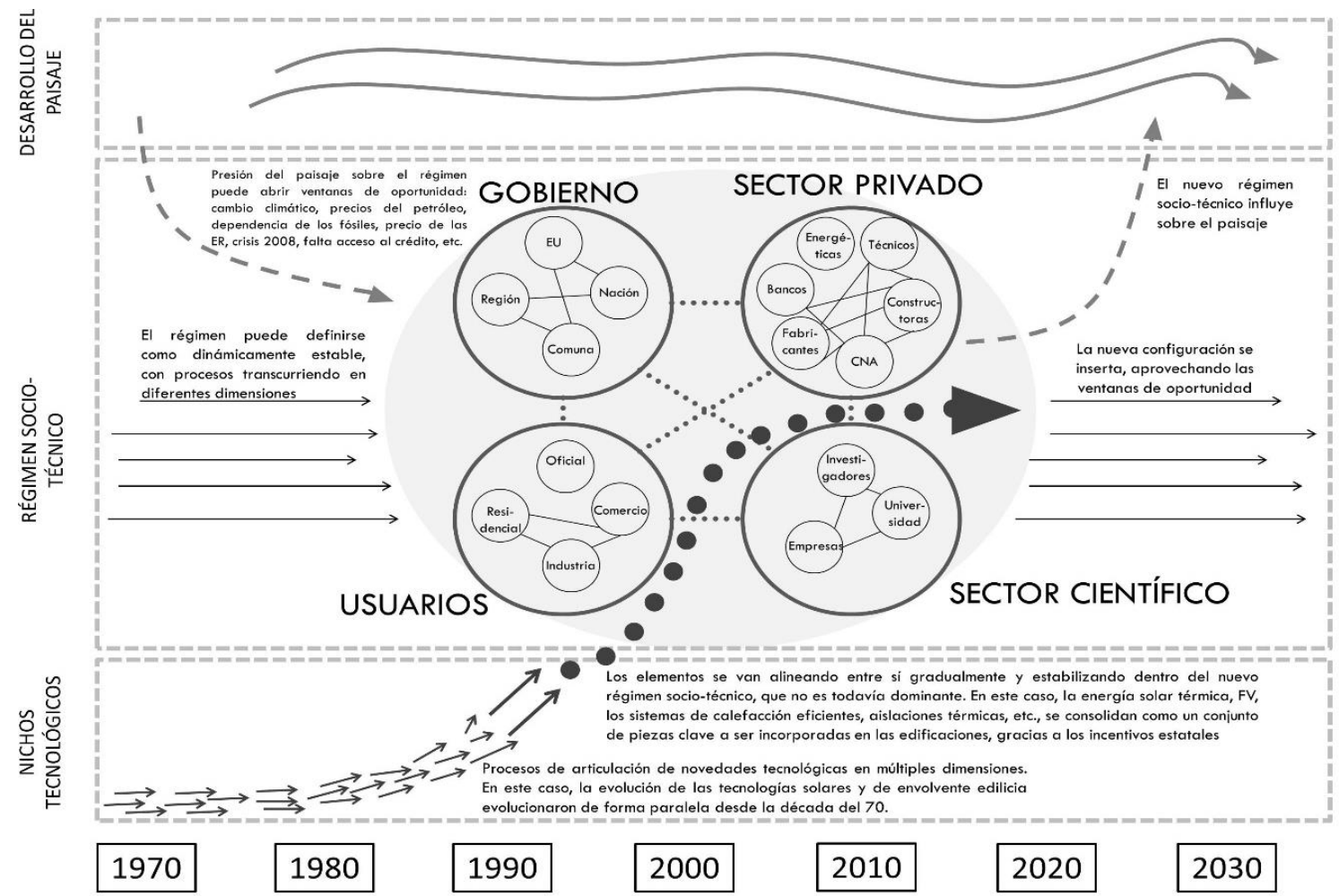

Figura 10.- Niveles de análisis y sus interacciones en el caso italiano. Fuente: adaptado de Elzen et al. (2004)

En este sentido, las políticas de incentivos estatales continúan siendo beneficiosas para la difusión de estas tecnologías y, al mismo tiempo, diferentes situaciones de paisaje o endógenas presionan para generar ventanas de oportunidad para que éstas emerjan hacia el nivel del régimen vigente (Figura 100). Esto es posible dado que se trata de tecnologías que se han desarrollado fuertemente desde la década de 1970 en el nivel de nicho y que alcanzaron un alto nivel de desarrollo, especialización y robustez. Sin embargo, también se detectan barreras en el mejoramiento de la edilicia existente, fundamentalmente por el impacto que causó la crisis de 2008 sobre el sector de la construcción, lo cual frena la construcción de nuevas viviendas de altas prestaciones energéticas.

Por otro lado, a partir del caso de estudio relevado - ciudad de Boloña-, es posible identificar que si bien los incentivos tienen un papel fundamental a la hora de lograr concretar los objetivos de ahorro energético propuestos por el Estado nacional; es de destacar la asociación/articulación público-privada en la oficina de "Punto Energia", la cual brinda soporte técnico y administrativo de forma gratuita para los usuarios.

Por su parte, si bien la sustitución total de las tecnologías convencionales aún no se ha logrado, hasta el momento existe una alta proporción de usuarios que han accedido a estas tecnologías. Tal como se relevó, alrededor de un $11,5 \%$ de las viviendas realizaron algún tipo de recalificación energética, lo cual genera un ahorro de 1,08 Mtep/año, cuyo valor es equivalente al consumo energético anual de más de 770 mil viviendas. 


\section{FACTORES CLAVE EN LA TRANSICIÓN TECNOLÓGICA ITALIANA}

En función del análisis del caso de estudio italiano, se identifican factores clave que han contribuido o dificultado el avance en la implementación de las nuevas tecnologías. Esta síntesis, a su vez, es de utilidad para generar insumos que sean de utilidad a la hora de la implementación de políticas públicas para el mejoramiento energético en otros países. Para ello, se estructuró la sistematización de la información mediante los niveles de paisaje-régimen-nicho (Tabla 3). A partir de esto es posible discutir aspectos fundamentales que necesariamente deben ser tenidos en cuenta en cualquier caso de estudio a la hora de implementar políticas para la promoción de EE y ER.

Tabla 3.- Factores clave para la difusión de ER y EE en el régimen socio-técnico.

\begin{tabular}{|c|c|c|c|}
\hline & Paisaje & Régimen & Nicho \\
\hline 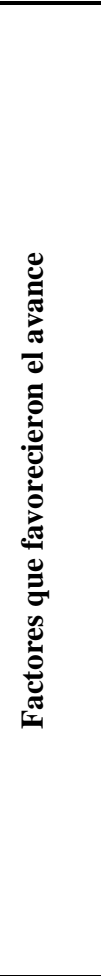 & $\begin{array}{l}\text {-Crisis del petróleo década de } \\
1970 \\
\text {-Dependencia de combustibles } \\
\text { fósiles } \\
\text {-Dependencia de importaciones } \\
\text {-Cambio Climático } \\
\text {-Descenso de los precios de las } \\
\text { energías renovables a nivel } \\
\text { mundial en la última década } \\
\text {-Precios del petróleo elevados } \\
\text { durante la última década que } \\
\text { superan el doble del valor del } \\
\text { período previo }\end{array}$ & $\begin{array}{l}\text {-Lanzamiento de políticas orientadas a las EE y ER a } \\
\text { nivel europeo (UE) } \\
\text {-Alineamiento político de Italia en relación a la UE, } \\
\text { readecuación del marco normativo y regulatorio nacio- } \\
\text { nal y lanzamiento de programas de incentivos directos } \\
\text { al usuario muy fuertes: "Conto Energia Fotovoltaico", } \\
\text { "Detrazione fiscale", "Conto Energia Termico" } \\
\text {-Capacidad de modificar los programas de incentivos en } \\
\text { base a las dificultades detectadas en la implementación } \\
\text { de los incentivos } \\
\text {-Los incentivos para recalificación energética en mu- } \\
\text { chos casos son adoptados por usuarios que indefecti- } \\
\text { blemente debían emprender trabajos en sus viviendas } \\
\text {-Tradición autonómica de las ciudades/regiones italia- } \\
\text { nas a la hora de readecuar sus normativas energéticas y } \\
\text { constructivas en un marco de escasa coordinación intra- } \\
\text { gubernamental } \\
\text {-Creación del foro "Covenant of Mayors" a nivel de } \\
\text { ciudades Europeas } \\
\text {-Asociación público-privada para la difusión de los } \\
\text { programas de incentivos y apoyo técnico (oficina "Pun- } \\
\text { to Energia") } \\
\text {-Las distintas tecnologías de EE y ER están lo suficien- } \\
\text { temente extendidas y la población conoce de su existen- } \\
\text { cia } \\
\text {-Las política de EE y ER sirvieron para movilizar la } \\
\text { economía, generar puestos de trabajo y ahorrar energía. }\end{array}$ & $\begin{array}{l}\text {-Desarrollo tecnológico } \\
\text { internacional de paneles FV } \\
\text { desde la década del 60/70, } \\
\text { generando un fuerte descenso } \\
\text { de precios desde } 100 \text { USD/W } \\
\text { en la década del } 70 \text { hasta } \\
\text { alcanzar un valor de } 1,38 \\
\text { W/USD en la actualidad. } \\
\text {-Desarrollo tecnológico } \\
\text { internacional de colectores } \\
\text { solares de agua desde 1900, } \\
\text { intensificación durante la } \\
\text { década del 70 y del } 90 \text { con la } \\
\text { tecnología de tubos de vacío. } \\
\text {-Desarrollo tecnológico para } \\
\text { el mejoramiento de la envol- } \\
\text { vente edilicia fundamental- } \\
\text { mente luego de la década del } \\
70 \text {, generando un entramado } \\
\text { de empresas que se pueden } \\
\text { dedicar a estos trabajos. } \\
\text {-Fuerte desarrollo en I+D en } \\
\text { los distintos sistemas, inclui- } \\
\text { dos los equipos destinados a } \\
\text { la calefacción: calderas a } \\
\text { condensación, bombas de } \\
\text { calor, entre otras. }\end{array}$ \\
\hline 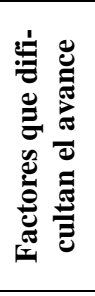 & $\begin{array}{l}\text {-Crisis económica de } 2008 \\
\text {-Gran cantidad de viviendas } \\
\text { vacantes de baja calidad termo- } \\
\text { energética construidas previas a } \\
\text { la crisis de } 2008 \\
\text {-Dificultad de acceso al crédito } \\
\text {-Alta proporción de la pobla- } \\
\text { ción de edad avanzada }\end{array}$ & $\begin{array}{l}\text {-La liberalización de los mercados energéticos aún no } \\
\text { genera los resultados esperados, los usuarios prefieren el } \\
\text { mercado cautivo gestionado por el Estado (Anderlini, } \\
\text { 2018) } \\
\text {-La normativa constructiva orientada a la eficiencia } \\
\text { energética en las nuevas edificaciones no tiene un im- } \\
\text { pacto significativo dado que la construcción de vivien- } \\
\text { das nuevas es marginal }\end{array}$ & $\begin{array}{l}\text {-Se detectan innovaciones en } \\
\text { materiales constructivos } \\
\text { como bloques con aislación } \\
\text { térmica incorporada, nuevas } \\
\text { aislaciones térmicas, y siste- } \\
\text { mas constructivos que aún no } \\
\text { logran penetrar en el régimen } \\
\text { vigente debido a sus costos }\end{array}$ \\
\hline
\end{tabular}
Fuente: elaboración propia.

Inicialmente, es preciso destacar que en el caso de estudio analizado, las medidas impulsadas por el gobierno buscaron generar ahorros en el consumo sin disminuir la habitabilidad en las viviendas. Para ello, la estrategia adoptada fue la promoción de la EE y las ER por medio de una fuerte política de incentivos directos al usuario; sobre la cual se generaron ciertas limitaciones en el acceso al crédito por parte de los usuarios que son necesarias de considerar. En relación a este aspecto, la creación de incentivos directos es fundamental en la reducción de la demanda energética; dado que, en contraposición con otro tipo de iniciativas, como por ejemplo los sistemas de bonificaciones/penalizaciones tarifarias respecto de consumos previos, su impacto es muy superior. Cabe mencionar que en el caso de Argentina, el sistema de bonificaciones/penalizaciones ha tenido resultados muy pobres (Recalde y Guzowski, 2012). 
Por su parte, se observa que es fundamental lograr una vinculación intra-gubernamental en materia de legislación para lograr alinear los intereses de las diferentes escalas jurisdiccionales (nación, provincia y municipio). Este es un aspecto que, tal como ocurre en el caso argentino, dificulta el avance de programas de eficiencia energética en las edificaciones (Chévez et al., 2017).

En tanto, en el caso de estudio, la promoción de incentivos para las medidas para mejorar la eficiencia energética residencial se orientó hacia los puntos críticos del consumo (envolvente edilicia y sistemas de calefacción) tanto para edificaciones nuevas como existentes. Este hecho es destacable dado que, si bien se trata de las intervenciones con mayor costo inicial, las mismas tienen un peso muy importante dentro de la demanda total residencial. En este sentido, aquellas medidas con un peso marginal dentro del consumo final y costos reducidos quedan a cargo de los usuarios; siendo el Estado el que asume la responsabilidad de brindar respuestas adecuadas para resolver las mayores dificultades energéticas.

En cuanto a las ER, Italia abordó su inserción a la matriz energética por medio de sistemas de alta potencia como así también de sistemas de baja potencia. En este sentido, la utilización de la energía solar térmica y FV de baja potencia se convierte en una oportunidad para comenzar a difundir su utilización y visibilización en ámbitos urbanos, cuya instalación puede ser complementaria de centrales de gran potencia, las cuales permiten generar respuestas a problemáticas diferentes.

Por otro lado, la disponibilidad de información al público respecto del uso de la energía y las posibilidades de mejoramiento de su vivienda es un aspecto clave, como así también la vinculación con aquellas empresas capaces de realizar los trabajos. Es por ello que las políticas de promoción, además de generar instrumentos de financiación y subsidios, precisan de una fuerte componente de publicidad, información, vinculación y gestión. En efecto, el monitoreo de los programas implementados permite verificar el avance de los mismos e introducir modificaciones para corregir las falencias detectadas.

Asimismo, a partir del análisis multinivel fue posible identificar que es fundamental la interpretación de las condiciones de contexto -o paisaje- que puedan incidir favorable o desfavorablemente sobre la implementación de las medidas. Algunos ejemplos son los costos internacionales de los combustibles, precios de bonos verdes, acuerdos firmados, etc. En este sentido, es necesario reconocer que el mejoramiento energético del sector residencial es un proceso de transición tecnológica de largo plazo, cuyos resultados pueden demoraron varias décadas. Por último, es destacable que el impulso de estas medidas ha logrado generar un nuevo mercado de trabajo, el cual moviliza a la economía en un contexto de crisis económica. Esto se convierte en una oportunidad para diversos países, dado que el fomento de estas actividades permite reducir la demanda energética, y con ello las importaciones de energía; activar diferentes ramas productivas; generar puestos de trabajo; mejorar la habitabilidad de las viviendas; entre otros factores.

\section{CONCLUSIONES}

El desarrollo del presente trabajo ha permitido identificar, describir y extraer los factores clave del proceso de transición tecnológica que se está llevando a cabo en el sector energético residencial italiano. Dicho régimen socio-técnico se encuentra migrando desde un sistema de base de consumidores de energía con baja eficiencia energética en la edificación y en los equipos, con generación eléctrica concentrada, estatal y altamente dependiente de los combustibles fósiles; hacia un sistema futuro con prosumidores distribuidos, orientados a la electrificación de los usos finales de energía, con alta eficiencia energética constructiva y de equipamiento, con prevalencia de generación concentrada de libre mercado con una alta participación de fuentes de ER.

En esta transición se pudo identificar que la implementación de las fuertes políticas de in- 
centivos impulsadas por el Estado, junto con las adecuaciones de los incentivos en función de la detección de barreras en su implementación, ha permitido hacer emerger a las tecnologías de EE y ER desde sus nichos tecnológicos en los cuales se habían desarrollado largamente. Asimismo, las condiciones de paisaje favorecieron la apertura de oportunidades dentro del régimen vigente para que las mencionadas tecnologías encontraran competitividad con las tecnologías previas. Algunas de ellas son la alta dependencia de los combustibles fósiles, los cuales mayormente son importados, de los incrementos en los precios internacionales del petróleo y el descenso de los precios de las ER. Por otro lado, la crisis económica internacional de 2008 condicionó fuertemente el avance de ciertas políticas energéticas por la dificultad de acceso al crédito para los usuarios y por la escasa incorporación de nuevas edificaciones de altas prestaciones termo-energéticas. Sin embargo, el Estado italiano fue capaz de interpretar dicho contexto y direccionar medidas específicas hacia las construcciones existentes, situación que no se podría llevar a cabo con políticas restrictivas.

Por otro lado, el marco conceptual utilizado demostró ser de utilidad para el análisis de esta transición, dado que permitió relevar aspectos clave en una situación de flujo tales como percepciones, reglas y vínculos socio-técnicos; los cuales generan el contexto para las acciones. En relación a ello, fue posible identificar y sintetizar los factores clave que han favorecido o dificultado el avance de la mencionada transición en el caso de estudio. Dicha síntesis de lecciones aprendidas sirvió para obtener conclusiones que pueden ser de interés para los organismos de planificación energética de aquellos países que estén comenzando o pretendan impulsar una transición similar.

\section{REFERENCIAS BIBLIOGRÁFICAS}

ADEME. The Odyssee-Mure project: energy efficiency gains in households since 2000. París: Agence de l'environnement et de la maitrise de l'energie, 2018.

ALBERINI, A., BIGANO, A. How effective are energy-efficiency incentive programs? Evidence from Italian homeowners. Energy Economics, v. 52, p.S76-S85, 2015. DOI: https://doi.org/10.1016/j.eneco.2015.08.021

ANDERLINI, E. (13 de Febrero de 2018): Miembro del equipo de trabajo de "Federconsumatori Bologna". (Chévez, P., Entrevistador)

ANTONINI, E. (6 de Febrero de 2018): Profesor de Tecnología de la Arquitectura de la Universidad de Bologna, Departamento de Arquitectura. Dr. en Tecnología de la Arquitectura . (Chévez, P., Entrevistador)

ARDANCHE, M., BIANCO, M., COHANOFF, C., CONTRERAS, S., GOÑI, M., SIMÓN, L. The power of wind: An analysis of a Uruguayan dialogue regarding an energy policy. Science and Public Policy, v. 44, p.1-10, 2017.

ARERA. Bilancio dell'energia elettrica. Roma: Autorità di Regolazione per Energia Reti e Ambiente, 2017.

ARERA. Bilancio del gas naturale. Roma: Autorità di Regolazione per Energia Reti e Ambiente, 2017.

CAPUTO, P., PASETTI, G. Boosting the energy renovation rate of the private building stock in Italy: Policies and innovative GIS-based tools. Sustainable Cities and Society, v.34, p.394-404, 2017.

CHANG, C.P., WEN, J., ZHENG, M., DONG, M., HAO, Y. Is higher government efficiency conducive to improving energy use efficiency? Evidence from OECD countries. Economic Modelling, v. 72, p. 65-77, 2017.

CHÉVEZ, P., MARTINI, I., DISCOLI, C. Políticas de eficiencia energética orientadas al sector residencial de la República Argentina. Revisión de trayectorias disímiles (2007-2015). Investigación Joven, v. 4, p.7-17, 2017.

ChiARONI, D., ChIESA, M., ChIESA, V., FRANZO, S., FRATtini, F., TOLETTI, G. Introducing a new perspective for the economic evaluation of industrial energy efficiency technologies: An empirical analysis in Italy. Sustainable Energy Technologies and Assessments, v. 15, p.1-10, 2016.

CNA. Information sheets on economic support instruments: Incentive rates (Fourth Conto Energia Fotovoltaico). Bologna: Confederazione Nazionale dell'artigianato e della Piccola e Media Impresa, 2011.

CNA. Information sheets on economic support instruments: Methods of "on-site exchange" ("scambio sul posto") for electricity from renewable sources. Bologna: Confederazione Nazionale dell'artigianato e della Piccola e Media Impresa, 2013. 
CNA. Information sheets on economic support instruments: Incentives for small energy efficiency measures and exploitation of renewable energy sources for thermal uses ("Conto Energia Termico"-Update 2016). Bologna: Confederazione Nazionale dell'artigianato e della Piccola e Media Impresa, 2016.

CNA. Information sheets on economic support instruments: "Fiscal detraction" for the energy requalification of the existing building stock ("Ecobonus") 2018 update. Bologna: Confederazione Nazionale dell'artigianato e della Piccola e Media Impresa, 2018.

COVENANT OF MAYORS OFFICE. Covenant of Mayors for Climate \& Energy. Bruselas; Unión Europea, 2018. Disponible en web: https://www.covenantofmayors.eu/en/

ELZEN, B., GEELS, F., GREEN, K. System Innovation and the Transition to Sustainability: Theory, Evidence and Policy. Chentelham: Edward Elgar Publishing, 2004.

ENEA. Rapporto Annuale sull'Efficienza Energetica 2017. Roma: Agenzia nazionale per le nuove tecnologie, l'energia e lo sviluppo económico sostenibile, 2018.

ENI Scuola. Lo scenario energetico in Italia. Roma: Ente Nazionale Idrocarburi, 2016.

ERBES, A., SUÁREZ, D. Repensando el desarrollo latinoamericano. Una discusión desde los sistemas de innovación. Los Polvorines: Universidad Nacional de General Sarmiento, 2016.

ESTIF. Solar Heat Interactive Statistics. Bruselas: European Solar Thermal Industry Federation, 2018. Disponible en web: http://solarheateurope.eu/publications/market-statistics/interactive-statistic/

FEDERAL RESERVE BANK OF ST. LOUIS. Crude Oil Prices: West Texas Intermediate (WTI). St. Louis: Federal Reserve Bank, 2018. Disponible en web: https://fred.stlouisfed.org/series/DCOILWTICO

FINI, G. (15 de Enero de 2018): Especialista en políticas de ahorro energético y sustentabilidad urbana en la Municipalidad de Bolonia. (Chévez, P., Entrevistador)

GAlATIOTO, A., CIULlA, G., RICCIU, R. An overview of energy retrofit actions feasibility on Italian historical buildings. Energy, v.137, p. 991-1000, 2017. DOI: https://doi.org/10.1016/j.energy.2016.12.103

GASPARI, M. (20 de enero de 2018): Doctor en Ciencia y gestión del Cambio Climático. Autor de tesis doctoral: "Innovative and sustainable electricity supply in a decentralised market: an analysis of business models, operators and regulation". (Chévez, P., entrevistador)

GASPARI, M., LORENZONI, A. The governance for distributed energy resources in the Italian electricity market: A driver for innovation. Renewable and Sustainable Energy Review, v.82, p.3623-3632, 2018. DOI: https://doi.org/10.1016/j.rser.2017.10.100

GEELS, F. Technological Transitions and System Innovations. A Co-Evolutionary and Socio-Technical Analysis. Chentelham: Edward Elgar Publishing, 2005.

GEELS, F., JOHNSON, V. Towards a modular and temporal understanding of system diffusion: Adoption models and socio-technical theories applied to Austrian biomass district-heating (1979-2013). Energy Research \& Social Science, v.38, p.138-153, 2018.

GEELS, F., MCMEEKING, A., PFLUGER, B. Socio-technical scenarios as a methodological tool to explore social and political feasibility in low-carbon transitions: Bridging computer models and the multi-level perspective in UK electricity generation (2010-2050). Technological Forecasting and Social Change (in press), 2018.

GSE. Statistical report 2016. Solar photoviltaics. Roma: Gestore de Servici Energetici, 2017.

IEA. Promoting energy efficiency investments. París: International Energy Agency, 2008.

IEA. Indicadores de Eficiencia Energética: Bases Esenciales para el Establecimiento de Políticas. París: International Energy Agency, 2015.

IRANZO, C. Carlota Pérez: Ventana de oportunidades después de la crisis financiera. Cuadernos del Cendes, v. 26, n.72, p.133-145, 2009.

IRENA. Cost and Competitiveness Indicators: Rooftop Solar PV. Abu Dhabi: International Renewable Energies Agency, 2017.

IRENA. Renewable Power Generation Cost in 2017. Abu Dhabi: International Renewable Energies Agency, 2018.

ISTAT. Energia-Consumo per uso domestico. Roma: Istituto nazionale di statistica, 2018 a. 
ISTAT. ISTAT. Il tuo accesso diretto alla statistica italiana. Roma: Istituto nazionale di statistica, $2018 \mathrm{~b}$.

KUNGL, G., GEELS, F. Sequence and alignment of external pressures in industry destabilisation: Understanding the downfall of incumbent utilities in the German energy transition (1998-2015). Environmental Innovation and Societal Transitions, v. 26, p.78-100. DOI: https://doi.org/10.1016/j.eist.2017.05.003

MiSE. Statistiche dell'Energia. Roma: Ministero dello Sviluppo Economico, 2018.

NAS. Energy for Rural Development. Renewable Resources and Alternative Technologies for Developing Countries. Washington, DC: National Academy of Sciences, 1976.

PARLAMENTO EUROPEO. Directiva 2012/27/UE. Brussels: Official Journal of the European Union, 2012.

PÉREZ, C. Revoluciones tecnológicas y capital financiero. La dinámica de las grandes burbujas financieras y las épocas de bonanza. Caracas: Polarin, 2003.

PRETE, I., PIPER, L., RIZZO, C., PINO, G., CAPESTRO, M., MILETI, A. Determinants of Southern Italian households' intention to adopt energy efficiency measures in residential buildings. Journal of Cleaner Production, v.153, p.83-91, 2017. DOI: https://doi.org/10.1016/j.jclepro.2017.03.157

RANIERI, C. (16 de Febrero de 2018): Referente de Políticas de ambiente, energía e investigación en la "CNA Bologna". (Chévez, P., Entrevistador)

RECALDE, M., GUZOWSKI, C. Boundaries in promoting energy efficiency: Lessons from the Argentinean case. International Journal of Hydrogen Energy, v. 37, p. 14725-14729, 2012.

REN 21. Renewables 2017 Global Status Report. París: REN21 Secretariat, 2017.

REN 21. Global Status Report Data Pack. Abu Dhabi: Renewable Energie Policy Network for the 21 Century, 2018.

ROGGE, K., PFLUGER, B., GEELS, F. Transformative policy mixes in socio-technical scenarios: The case of the lowcarbon transition of the German electricity system (2010-2050). Technological Forecasting and Social Change, 2018. DOI: https://doi.org/10.1016/j.techfore.2018.04.002

ROSENFELD, E. Las interacciones entre la energía y el hábitat en la Argentina. La Plata: EDULP, 2007.

RUNQING, H., PEIJUN, S., ZHONGYING, W. An overview of the development of solar water heater industry in China. Energy policy, v. 51, p. 46-51, 2012. Doi: https://doi.org/10.1016/j.enpol.2012.03.081

SARRICA, M., BIDDAU, F., BRONDI, S., COTTONE, P., MAZZARA, B. A multi-scale examination of public discourse on energy sustainability in Italy. Energy Policy, v. 114, p. 444-454, 2018.

SATTA, G. (12 de febrero de 2018): Arquitecto y presidente de la cooperativa "Società Cooperativa Costruire". (Chévez, P., Entrevistador)

SOLAR POWER AUTHORITY. Solar Power Resources. Recuperado el 7 de Abril de 2018, de https://www.solarpowerauthority.com/a-history-of-solar-cells/

All authors stated that they had: a) actively participated in the discussion of the results; and b) Review and approval of the final version of the paper.

This work is licensed under a Creative Commons Attribution 4.0 International License. CC-BY 